\title{
El yacimiento Sector XXIII de Velilla de San Antonio: Una contribución al conocimiento del Paleolítico en la Comunidad de Madrid
}

\section{The site of Sector XXIII of Velilla de San Antonio: A contribution to the knowledge of Palaeolithic in Madrid}

\author{
Alberto Mingo Álvarez ${ }^{*}$ \\ Jesús BARBA REY* \\ Miguel Ángel García Valero**
}

\begin{abstract}
RESUMEN ABSTRACT
En este artículo se presentan los trabajos de caracterización geomorfológica y prospección y excavación arqueológica desarrollados en el yacimiento del Sector XXIII de Velilla de San Antonio (Madrid).

Asimismo, se exponen los resultados procedentes del análisis tecno-tipológico de las piezas líticas recuperadas. Con la información disponible se han podido detectar dos posibles horizontes cronoculturales: un conjunto lítico exiguo proveniente de un momento indeterminado del Paleolítico inferior y otro conjunto más representativo que podría adscribirse

We present the works concerning the geomorphological features and the archaeological prospection and excavation developed in the site of Sector XXIII at Velilla de San Antonio (Madrid). Moreover, we showed the results and conclusions derived from the techno-typological analysis of the recovered lithic material. The available data has allowed to identify two possible chrono-cultural periods: a very short set of pieces coming from an undetermined moment of the Lower Palaeolithic and a bigger set which could be linked to a Mousterian phase.
\end{abstract} dentro del Musteriense.

* Departamento de Prehistoria y Arqueología, UNED, amingo@geo,uned.es; jbarba@ bec.uned.es

** Gestión de Patrimonio de la Delegación de Cultura de Guadalajara, magarciav@ jccm.es 


\section{PALABRAS CLAVE}

Geomorfología, Prospección y excavación arqueológica, Industria lítica, Velilla de San Antonio, Paleolítico inferior, Musteriense.

\section{KEY WORDS}

Geomorphology, Archaeological prospection and excavation, Lithic industry, Velilla de San Antonio, Lower Palaeolithic, Mousterian.

\section{MARCO GEOGRÁFICO Y GEOMORFOLÓGICO}

Velilla de San Antonio es una población de la Comunidad de Madrid que se encuentra a 25 kilómetros al Este de la capital, a una altitud media de 533 metros. Presenta un relieve plano y es atravesada por el río Jarama que conforma el eje principal de la hidrología de esta zona.

La parte central de la Comunidad de Madrid se caracteriza por contener depósitos miocenos que, en su mayor parte, están constituidos por materiales evaporíticos, particularmente bien reconocibles en los farallones de los valles del río Jarama, del río Tajuña y del río Tajo. No obstante, sobre estos depósitos evaporíticos se disponen sedimentos carbonáticos de edad igualmente Miocénica, aunque algo más reciente. La diferencia entre unos y otros materiales superpuestos en áre-

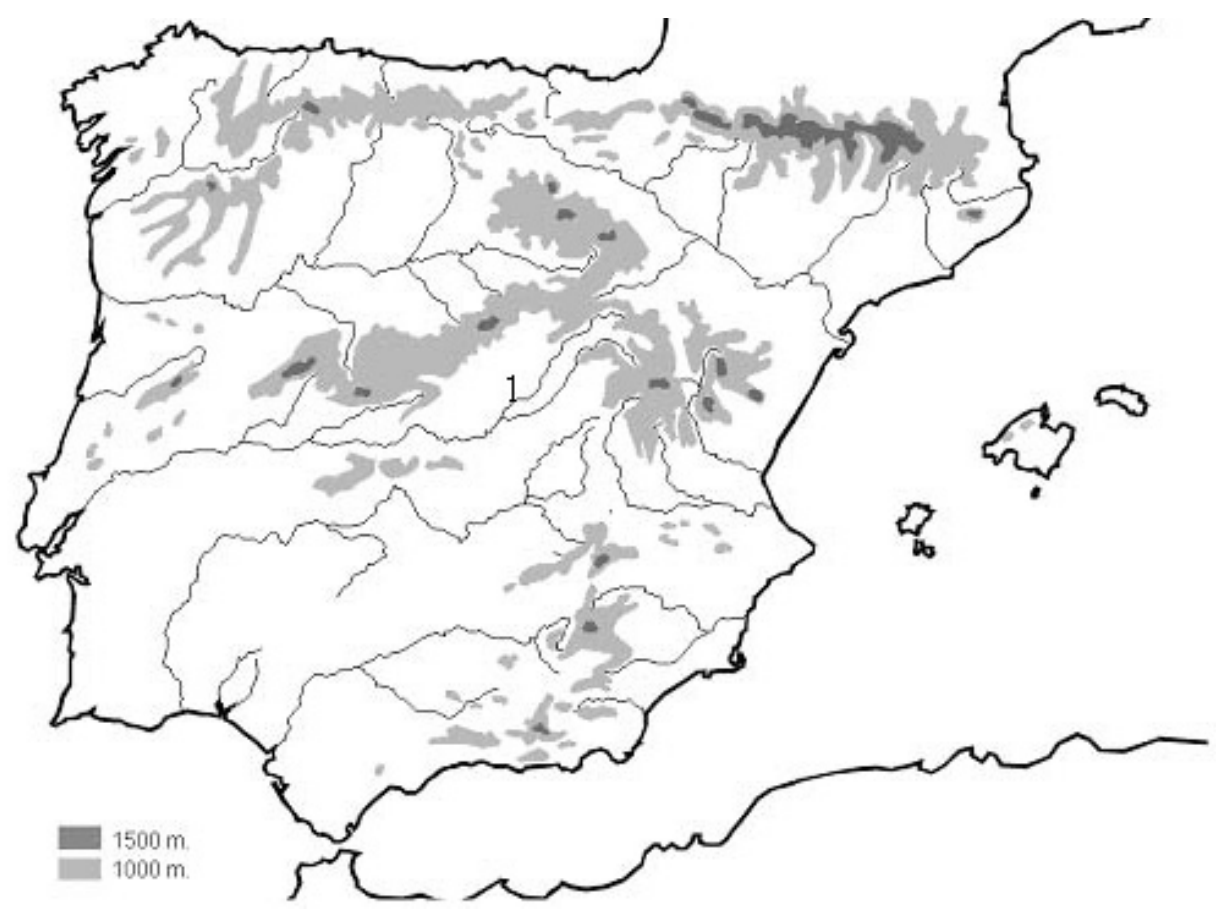

Fig. 1. Situación del yacimiento «Sector XXIII» de Velilla de San Antonio (Madrid). 
as centrales de la cuenca pone de manifiesto la existencia de unidades estratigráficas distintas dentro del registro mioceno de la región. Estas unidades han sido denominadas Unidad Inferior, Unidad Intermedia y Unidad Superior (Alberdi, 1985). Una descripción detallada de estas unidades puede encontrarse en Junco y Calvo (1983). Entre el depósito de la Unidad Inferior y el depósito de la Unidad Intermedia tuvo lugar una reactivación importante del relieve de la Sierra, que contribuyó a la expansión de los abanicos aluviales arcósicos hacia el sur. Todos estos depósitos se sedimentaron en lagos cerrados, de muy escasa profundidad, rodeados por abanicos aluviales (Calvo et al., 1989). Este panorama cambió durante el Mioceno superior, debido a un nuevo reajuste tectónico de la región, de forma que la sedimentación en este último periodo estuvo controlada por fallas N-S, desarrollándose cursos fluviales de esta dirección que acumularon gravas y arenas, erosivamente discordantes sobre los estratos de la Unidad Intermedia del Mioceno. El contacto entre esta unidad y los sedimentos suprayacentes viene además marcado por una importante superficie de karstificación. El techo del Mioceno superior está formado por calizas, comúnmente conocidas en la región como Calizas del Páramo, que se depositaron en lagos de agua dulce muy someros. Por último, los sedimentos de edad pliocénica forman una delgada capa de sedimentos, fundamentalmente terrígenos que, en partes centrales de la cuenca, está cubierta por una costra calcárea de algunos metros de espesor, que constituye el depósito más reciente previo al encajamiento de la red fluvial cuaternaria.

La evolución geológica cuaternaria en la Depresión Terciaria (Pérez-González, 1994) es una historia muy influenciada por los procesos de erosión fluvial o vaciado de los materiales terciarios que la rellenan, más que por los procesos de acumulación. Sin embargo, hay extensos afloramientos de depósitos de terrazas en los valles principales que drenan la Comunidad de Madrid (ríos Jarama, Henares, Manzanares y Tajo, en el sur). Las terrazas más altas del Pleistoceno inferior (más antiguas de 780.000 años), se encajan en dos altiplanicies que dominan los relieves madrileños: el piedemonte de la Raña al norte, y el páramo calizo o Alcarria al este del valle del río Jarama. Estas terrazas del Pleistoceno inferior están, en cotas relativas, más de 200 metros sobre los cauces. Las terrazas más recientes del Pleistoceno medio (entre 120.000 y 780.000 años) contienen en los valles de los ríos Manzanares y Jarama importantes yacimientos arqueo-paleontológicos, como el yacimiento de Áridos de Arganda, o los muy numerosos en el cauce bajo del río Manzanares, a su salida de Madrid.

El Mesozoico y el Paleógeno están afectados por varias fases de plegamiento apareciendo como fundamentales la directriz Guadarrama, la directriz Altamira y la Ibérica. El Neógeno se presenta subhorizontal o levemente inclinado hacia los bordes. Existen evidencias de actividad geotectónica reciente que afecta a todo el conjunto del Sistema Central y a la Cuenca Meso-terciaria del Tajo, con grandes alineaciones morfoestructurales definidas por los ríos Henares y Jarama. Geomorfológicamente destacan sistemas de glacis, escarpes en valles disimétricos y relieves en graderío, debidos a las terrazas de los ríos Henares y Jarama. 
El término de Velilla de San Antonio está asentado sobre materiales geológicos terciarios y cuaternarios, fundamentalmente, siendo estos últimos los que afloran en superficie. Los materiales terciarios están compuestos por yesos masivos y tableados y forman parte del denominado «Dominio Terciario», que son el resultado del funcionamiento centrípeto de sistema lacustre hidrológicamente cerrado, en el que las orlas de sedimentos detríticos, abastecidos desde los relieves montañosos circundantes, gradan lateralmente a depósitos terrígenos más finos y, finalmente, en las zonas centrales de las cuenca, a depósitos de precipitación química de carácter evaporítico. La paragénesis mineralógica de estas facies evaporíticas es bastante compleja. Estos materiales terciarios se incluyen dentro de la Unidad Inferior del Mioceno (Junco y Calvo, 1983). La interpretación de los depósitos evaporíticos en esta parte de la Cuenca de Madrid es objeto de controversia, aunque parecen pertenecer a unos depósitos de lagos playa-salinos. Al no encontrase restos paleontológicos en estos niveles evaporíticos, su edad viene determinada por la unidad suprayacente, estableciéndose como Orleandiense (Aragoniense inferiormedio).

El Cuaternario está representado por las terrazas del río Jarama y sus llanuras de inundación, así como por fondos y barras aluviales, conos de deyección y coluviones y depósitos de pie de talud. Las terrazas tienen litofacies del tipo grava y cantos, coordinadas a menudo por limos (arcillas arenosas), siendo menos abundantes las arenas (terrazas de Mejorada y arroyo Pantueña). Las gravas y cantos son poligénicas (cuarcitas, cuarzos y calizas del Páramo; a veces micacitas, gnéises y granitos). Los coluviones, los depósitos de pie de talud, los conos de deyección, las llanuras de inundación, fondos de valles y barras aluviales están formados por estas gravas y cantos. La edad de estos depósitos cuaternarios es Pleistoceno medio-Holoceno.

\section{ANTECEDENTES}

El Valle del Jarama Madrileño y dentro de éste el término municipal de Velilla ofrece una secuencia cultural bastante amplia, alcanzando desde los primeros pobladores y asentamientos paleolíticos hasta nuestros días.

Los primeros restos paleolíticos que se localizan en el valle del Jarama se atribuyeron al Paleolítico Inferior, concretamente al Achelense Medio y Final. Algunos de estos hallazgos paleolíticos se ha podido comprobar que correspondían a lugares de ocupación dedicados preferentemente al aprovechamiento de grandes mamíferos como elefantes, hipopótamos, etc. En los años 70 del siglo XX, en el Valle del Jarama (en la orilla izquierda del río Jarama, a menos de $3 \mathrm{~km}$. al S.E. de su confluencia actual con el Manzanares) —zona del puente Arganda - fueron localizados y excavados con metodología arqueológica dos de los yacimientos paleolíticos más antiguos e importantes de la Comunidad de Madrid (Áridos I y II). En ellos se hallaron restos de animales y útiles en piedra realizados por el hombre que 
pusieron de manifiesto que hace unos 350.000 años el Valle del Jarama era frecuentado por grupos de cazadores (Santonja y Querol, 1991).

El sitio de Áridos I fue localizado por los obreros de la empresa Áridos S.A. (1971) que en el curso de sus trabajos descubrieron los restos de dos defensas de elefante. La superficie de excavación supuso unos $6 \mathrm{~m}^{2}$ y fue interrumpida cuando se comprobó que se trataba de un yacimiento arqueológico in situ, con una asociación faunística excepcional, pues se registró ya entonces la presencia de abundantes vertebrados de pequeña talla, además de Palaeoloxodon antiquus e industria lítica.

Los restos líticos que se localizaron en la excavación del sitio aparecieron con las aristas frescas, sin ninguna huella de erosión fluvial ni de ningún otro tipo. Se documentaron lascas partidas in situ, muy probablemente por efecto de pisadas, y numerosos remontajes cuya dispersión permite establecer relaciones entre diversas áreas. Todo hace pensar que estos restos se encontraban absolutamente in situ, sin que el medio que depositó los materiales que cubrían el yacimiento hubiera poseído competencia suficiente para provocar desplazamientos importantes de los restos arqueológicos.

En ningún punto de las superficies excavadas se detectó la presencia de alguna modalidad de estructura artificial; ni siquiera de rocas alóctonas no relacionables con la industria lítica (manuports). Se dedicaron importantes cuidados a encontrar restos de carbones o de maderas; sin embargo, los esporádicos restos de carbón recuperados - de dimensiones milimétricas - no permiten afirmar nada seguro respecto al uso del fuego por los primitivos ocupantes. Ocasionalmente apareció también algún hueso con huellas de haber sido quemado, y también diversos fragmentos de un bloque de sílex con un lustre característico de haber sido sometido a un calentamiento brusco. En ninguno de estos casos puede eliminarse con total seguridad la influencia de incendios naturales, que en el caso del bloque de sílex han podido afectarle incluso antes de ser recogido por los homínidos que desarrollaron sus actividades por estas tierras entre las que se incluye Velilla; pero si algún incendio natural hubiese afectado al yacimiento es bastante probable que una mayoría de los huesos recogidos en el yacimiento presentase trazas de fuego, cosa que no ocurre y permite pensar, dentro de un margen razonable de incertidumbre, que los primitivos ocupantes emplearon de alguna manera el fuego en sus actividades en este lugar.

El yacimiento de Áridos II, 220 m. al N.E. de Áridos I, se descubrió al comienzo de la campaña de excavaciones de 1976. En una prospección del arenero se comprobó la existencia de restos de elefante, puestos al descubierto inadvertidamente por una pala excavadora de la explotación industrial. La limpieza de los restos que afloraban permitió apreciar su asociación con industria lítica, así como la pequeña superficie del yacimiento $\left(7 \mathrm{~m}^{2}\right)$. El conjunto había sido afectado al N. y E. por dos canales, que transportaron o desplazaron los restos que encontraron a su paso. La pala excavadora dispersó otros elementos, especialmente al $\mathrm{S}$. de la falla inferior. 
Los restos óseos conservados corresponden a un individuo adulto, probablemente macho, atribuido a Palaeoloxodon antiquus. El elefante yacía apoyado sobre su costado derecho y en una superficie consolidada. Hay evidencia de que el hombre manipuló estos restos: seis vértebras cervicales (falta el atlas) aparecieron en conexión con las dos primeras dorsales y separadas cuarenta centímetros de la tercera dorsal; se encontró un fragmento craneal con una esquirla de sílex incrustada, en el extremo opuesto al que anatómicamente le correspondía. Además está el resto de la industria lítica claramente asociada con este esqueleto. Del mismo modo, junto al esqueleto aparecieron veintiocho objetos líticos, claramente asociados con él, y un bifaz y un hendedor que deben pertenecer a este conjunto, pero que habían sido desplazados por la pala excavadora. También aparecieron cuatro lascas en las mismas circunstancias.

Si desde el punto de vista cualitativo se encuentran paralelismos entre este conjunto y Áridos I, desde el cuantitativo se aprecian diferencias entre los dos sitios de ocupación. Fuera de las densidades de objetos líticos respectivas, no muy alejadas, se han señalado diferencias importantes en cuanto a los porcentajes en peso de los diferentes grupos de utensilios, la dispersión de restos óseos -agrupados aquí y diseminados en el otro-, la ausencia de otra fauna que no sea elefante en Áridos II y la relación entre el número de nódulos diferentes empleados en la talla y el número de objetos de cada nódulo recuperados. Estos datos parecen indicar, por un lado, que el porcentaje de superficie de yacimiento original conservado es menor en Áridos II que en Áridos I y, por otro, que los restos de este elefante se sometieron a manipulaciones menos intensas, más primarias, que en el caso de Áridos I, donde aparecen más diseminados.

De menor importancia pero igualmente reseñables, especialmente por la proximidad al yacimiento objeto de este estudio (Sector XXIII), se encuentran:

- La zona arqueológica de «La Presa», al Norte de nuestro ámbito de estudio, y ya en el vecino término de Mejorada del Campo, ocupando gran parte de la extensión del mismo (108 ha). Esta área arqueológica presenta la categoría de BIC a partir de una resolución del 13 de diciembre de 1991 e incluye 34 yacimientos arqueológicos. La cronología de todos estos yacimientos va desde el paleolítico hasta etapas contemporáneas (Antona del Val, 1993).

- «Rompe Rejas», situado también en Mejorada del Campo. Se trata de un yacimiento de cronología paleolítica bastante alterado por una escombrera, que se sitúa a escasos metros al norte del límite del yacimiento Sector XXIII (Antona del Val, 1993).

- Yacimiento n. ${ }^{\circ}$ 167016, dentro del término de Velilla de San Antonio. Presenta una pequeña dispersión de material lítico al norte del casco urbano. Fue localizado en 1989 por Francisco Javier Pastor Muñoz en una prospección para la CAM (Antona del Val, 1993). 


\section{TRABAJOS DE PROSPECCIÓN Y EXCAVACIÓN ARQUEOLÓGICA}

En el yacimiento denominado "Sector XXIII de Velilla de San Antonio» se han llevado a cabo dos fases de trabajos arqueológicos. La primera consistió en el desarrollo de una prospección arqueológica visual de cobertura total y una prospección geo-paleontológica. Estas labores supusieron la inspección directa y exhaustiva de una superficie de terreno de morfología trapezoidal y $390.000 \mathrm{~m}^{2}$ aproximadamente mediante una serie de batidas de prospectores separados a intervalos regulares de unos 5 metros. El resultado fue la delimitación de 11 áreas con material arqueológico superficial (industria lítica), para cada una de las cuales se generó un polígono a partir de coordenadas UTM que permitió su referencia espacial. 8 de estas zonas coinciden con acumulaciones de material y el resto lo constituyen elementos aislados. El estudio geo-paleontológico, por su parte, concretó que los materiales observados han sido transportados por arrastres de fondo y por saltación, con un dominio de los materiales cuarcíticos. Se apreció igualmente que los cantos y bloques han sufrido un tipo de desgaste que ofrece analogías con los depósitos fluviales actuales.

El conjunto lítico procedente de la prospección se compone de 42 piezas. La principal característica que muestra todo el material es la citada alteración que sufre. Hemos constatado efectos de rodamiento, tanto en las piezas en cuarcita como en sílex, si bien es más observada sobre las cuarcitas. Algunos restos de sílex muestran contrariamente unos filos bastante frescos. La deshidratación es un proceso muy extendido en mayor o menor grado en todo el material realizado en sílex. Asimismo, debemos señalar la presencia de superficies concrecionadas en un buen número de piezas, indistintamente de la materia prima. El rodamiento observado probablemente responde, a tenor de las conclusiones del estudio geopaleontológico, a procesos mecánicos, probablemente por arrastre fluvial dado que este material ha sido recogido en una terraza del río Jarama. Finalmente, hemos apreciado en algunas piezas «pseudo-retoques». Esta alteración es también coherente con la disposición de este yacimiento (explotación agrícola del terreno).

Otra característica que define al conjunto es, a pesar de la dualidad de la materia prima trabajada, el predominio de las piezas en sílex. El material está realizado sobre cuarcita de grano grueso $(n=7)$ y sílex $(n=35)$

El análisis tecno-tipológico de la muestra nos ha aportado información interesante (Figura 2). Se documentan 5 núcleos, 3 de ellos informes (Figura 3); uno, claramente, discoide (Figura 4); y, por último, otro bifacial de concepción discoide. Son, por lo general, de pequeñas dimensiones, presentándose bastante agotados. Los 3 núcleos informes tienen más de dos planos de percusión. Se han hallado igualmente: 2 cantos trabajados en cuarcita que comparten la característica de ser ambos unifaciales (choppers) (Figura 5); 1 bifaz subtriangular que destaca por su tamaño no muy grande, sus bordes rectos y una asimetría reseñable en sus caras (Figura 6); 2 raederas sobre lascas de pequeñas dimensiones que contienen algo 
de córtex en su cara dorsal. Una exhibe su retoque en el lateral recto derecho (Figura 7), mientras que la otra lo alberga en los dos laterales (convergente recta); 2 escotaduras con retoque tipo denticulado (una en cuarcita y otra en sílex); 1 denticulado; 2 raspadores (Figura 8); y 4 lascas retocadas de reducidas dimensiones. El retoque que se observa en los útiles sobre lasca suele ser abrupto y continuo, apareciendo de manera directa preferentemente.

Asimismo, debemos mencionar el hallazgo de 4 aristas de núcleo y 1 semitableta. Todas ellas en sílex. Este tipo de piezas es un signo claro del desarrollo de actividades orientadas al acondicionamiento de los núcleos. El resto del material lo integran lascas simples que destacan por su reducida longitud y anchura. Prácticamente todas las lascas del conjunto, tanto las que conforman útiles como las que no, se presentan en sílex, y suelen tener un tamaño medio-pequeño. Esta apreciación concuerda con lo advertido en los núcleos, encontrándose éstos bastante explotados y orientados a una obtención de soportes (lascas) reducidos. Este aspecto muy probablemente responde a estrategias tecnológicas, aunque pudiera estar influenciado por las dimensiones de los nódulos de sílex disponibles en las fuentes de aprovisionamiento más cercanas.

En una segunda etapa de estudio de este yacimiento se desarrollaron trabajos de excavación en dos catas de la zona 1 (denominadas catas 1 y 2), que coincidía con el área de mayor densidad de restos recogidos en la prospección. Las catas tenían unas dimensiones de $3 \times 2$ metros y estaban, a su vez, divididas en 6 cuadrículas de un metro cuadrado.

Se distinguieron 3 niveles estratigráficos:

- Niveles 1 y 2: Se caracterizan por la presencia de arenas de grano fino con matriz arcillosa y cantos de cuarcita centimétricos. La diferenciación entre los dos reside en el hecho de que el nivel 2 presenta un componente mucho más arcilloso que el 1, junto con una diferenciación del color del sedimento.

El nivel 1 alberga una potencia de unos $25 \mathrm{~cm}$., mientras que el nivel 2 tiene una potencia de entre 6 y $10 \mathrm{~cm}$.

- Nivel 3: Conglomerado con matriz carbonática, con gran presencia de cantos de cuarcita. Presenta una gran dureza y compactación.

El material lítico estudiado se compone de un conjunto exiguo de 17 (15 piezas en la cata 1 y las dos restantes en la cata 2). La cercanía de las dos catas y el número reducido de elementos nos ha motivado a estudiar como un único grupo. Por tanto, las conclusiones derivadas del análisis del material no deben ser tomadas como categóricas.

Todas las piezas han sido realizadas en sílex. Nuevamente, la característica más común de este material es la presencia de diversos tipos de alteración que afecta en grado variable a su superficie. Así, hemos advertido efectos de rodamiento, deshidratación y, en menor medida, pátinas y concreciones. 
El análisis del material nos ha permitido reconocer los aspectos tecno-tipológicos de las piezas (Figura 2). Así, hemos podido documentar: 2 núcleos, uno discoide (Figura 9) y otro informe, ambos de pequeñas dimensiones y bastante agotados; 3 raederas, 2 de ellas simples rectas y otra transversal recta; 1 muesca de tipo denticulado (Figura 10); 3 lascas retocadas; 1 lasca de acondicionamiento de núcleo; y 7 lascas simples, en su mayoría de pequeñas dimensiones y angulares.

\begin{tabular}{|l|l|c|c|}
\hline \multicolumn{2}{|c|}{ Material lítico } & Prospección & Excavación \\
\hline \multirow{3}{*}{ Núcleos } & Discoides & 2 & 1 \\
\cline { 2 - 4 } & Informes & 3 & 1 \\
\hline \multirow{3}{*}{ Útiles nucleiformes } & Cantos trabajados & 2 & \\
\cline { 2 - 4 } & Bifaces & 1 & 3 \\
\hline \multirow{3}{*}{ Útiles sobre lasca } & Denticulados & 1 & 1 \\
\cline { 2 - 4 } & Lascas retocadas & 4 & 3 \\
\cline { 2 - 4 } & Muescas & 2 & 1 \\
\cline { 2 - 4 } & Raederas & 2 & 7 \\
\cline { 2 - 4 } & Raspadores & 2 & 17 \\
\hline Productos de acondicionamiento & 5 & 18 & \\
\hline \multicolumn{2}{|c|}{ Tascas simples } & 42 & \\
\hline \multicolumn{2}{|c|}{ Total } & & 2 \\
\hline
\end{tabular}

Fig. 2. Cuadro tipológico de las piezas líticas recuperadas en la prospección y excavación arqueológica.

Al igual que las lascas del conjunto recuperado en la prospección, las procedentes de la excavación, tanto las que conforman útiles como las que no, suelen tener un tamaño medio-pequeño. El alto grado de explotación de los dos núcleos parece apuntar a una gestión de los mismos orientada a la obtención de soportes (lascas) reducidos. Aunque es una apreciación atrevida, esta relación podría ser indicativa del desarrollo de determinadas estrategias tecnológicas. Finalmente, se debe mencionar que el retoque suele ser abrupto, directo y, generalmente, continuo.

La comparación entre los conjuntos recogidos en la primera fase de prospección y los recuperados en las labores de excavación de los dos sondeos manuales nos ha orientado en el reconocimiento de ciertas características que se detallan a continuación:

- La cuarcita desaparece del material proveniente de las catas.

- Los útiles nucleiformes (tallados en cuarcita) no han sido documentados durante la excavación. Por el contrario, se registró una significativa presencia de éstos en el conjunto de piezas halladas en la prospección. 
- La alteración es un factor constatado en ambos grupos de piezas, especialmente rodamiento y desilificación.

- Las útiles en sílex, recogidos tanto en la prospección como en los sondeos, podrían adscribirse, con cierta laxitud, a algún momento del Paleolítico medio.

- Los núcleos son de un tamaño relativamente pequeño, presentándose bastante agotados. Debemos destacar la aparición en ambos casos de núcleos de reducción discoide, de un tipo característico del Musteriense.

- Las lascas (simples y retocadas) son, en su mayor parte, de un tamaño medio-reducido.

Por último, debemos mencionar en este apartado que para completar este estudio se han llevado a cabo una serie de análisis sedimentológicos y micropaleontológicos (lavado y cribado de muestras de sedimentos). Así, hemos constatado que el área de estudio representa una zona de alto componente dinámico, donde los sedimentos muestran un alto grado de arrastre y transporte, tanto por una dinámica fluvial como por movimientos de ladera, tipo glacis. Por su parte, desde el punto de vista micropaleontológico, no se han encontrado restos en ninguna de las muestras analizadas.

\section{ATRIBUCIÓN CULTURAL Y VALORACIÓN FINAL}

El escaso número de piezas recogido, junto con la ausencia de datos ambientales (fauna y flora), dificulta la atribución cultural de este conjunto con total certeza. No obstante, el examen de la caracterización del material si que permite postular, aunque con las debidas reservas, una adscripción crono-cultural aproximada que evidentemente es amplia.

El conjunto observado parece proceder de dos horizontes culturales diferentes. El primero se atisba en el grupo de piezas recuperadas en la excavación y en la mayoría de las piezas halladas durante las labores de prospección. El segundo parece apreciarse en un grupo concreto de piezas procedente de la prospección.

El primer grupo se caracteriza por los siguientes aspectos: predominio de material en sílex; los soportes son relativamente pequeños (lascas no retocadas, retocadas, y útiles) y de escaso espesor; los núcleos están casi agotados, presumiblemente orientados a la extracción intencional de soportes de segunda generación de dimensiones reducidas; se documentan dos núcleos discoides (entre ellos la única pieza en cuarcita de todo este grupo), y un producto de acondicionamiento procedente de un tercer núcleo discoide (semitableta); ausencia de útiles nucleiformes; por último, este conjunto de útiles se compone de raederas, raspadores, muescas y un denticulado. A tenor de estas características, nos inclinamos a atribuir este conjunto a un momento indeterminado dentro del tecno-complejo Musteriense. 
El segundo grupo que creemos identificar tan solo se compone de 5 piezas, que muestran las siguientes particularidades: todas ellas han sido ejecutadas en cuarcita de grano grueso; la alteración que sufren es principalmente un fuerte rodamiento; 3 de las piezas son útiles nucleiformes (2 cantos trabajados unifaciales y 1 bifaz subtriangular); la muesca y la lasca recogidas son de tamaño y espesor considerable, mucho mayor que los advertidos para las piezas en sílex; finalmente, el bifaz es espeso, con gran asimetría, de talla sumaria e importantes restos de córtex (principalmente en su base globular), aunque exhibe unos bordes bastante rectos. Estas características difieren notablemente de las apuntadas para el anterior grupo de elementos, de modo que pensamos que es probable que estos últimos restos pertenezcan a otro período crono-cultural, sin duda más arcaico. En nuestra opinión, se podría adscribir sin dificultad a un Paleolítico inferior indeterminado, si bien no muy avanzado.

Considerando la distribución espacial de las zonas arqueológicas encontradas, así como el tamaño de las piezas y las características superficiales de alteración, que en la mayoría de los casos presentan rodamiento y deshidratación, parece deducirse que son materiales arqueológicos removilizados, en mayor o menor medida, desde zonas de curso fluvial más alto que el del área de estudio, al comportarse todo el conjunto arqueológico como clastos durante el arrastre de sedimentos por la dinámica fluvial del río, siendo depositados diferencialmente en áreas donde dicha dinámica fluvial fuese menor, según tamaños y formas de los mismos. De acuerdo con estos datos se puede pensar que la geomorfología de la zona, un área extensa de terrazas erosionadas por agentes atmosféricos, con las alteraciones post-depositacionales constatadas, ha podido contribuir en la dispersión y mezcla de evidencias líticas de poblamiento paleolítico de diferentes horizontes cronológicos.

Con las limitaciones reseñadas, el hallazgo y estudio de esta industria vienen a completar y enriquecer el conocimiento del poblamiento paleolítico en este tramo del Jarama y de regiones próximas.
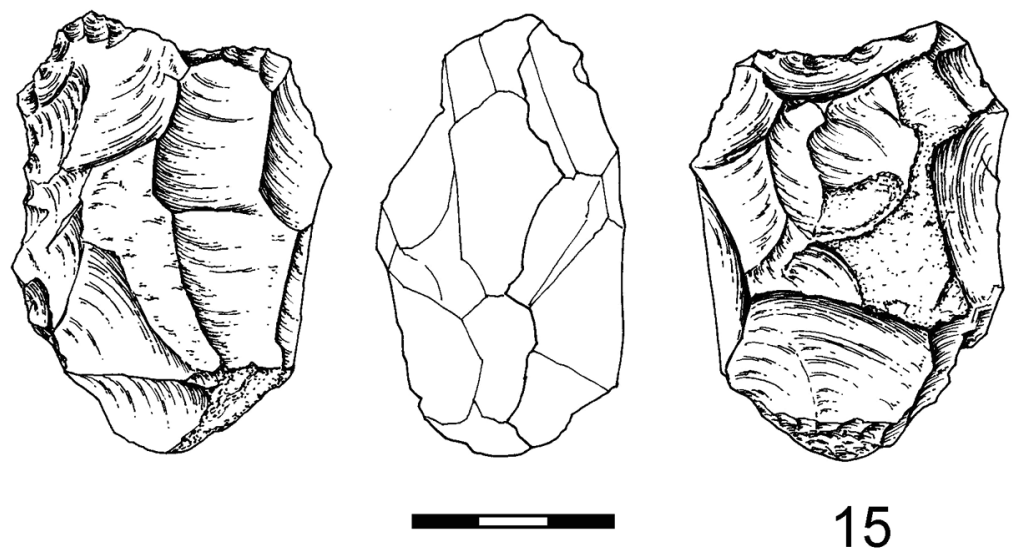

Fig. 3. Núcleo informe (procedente de la prospección). 

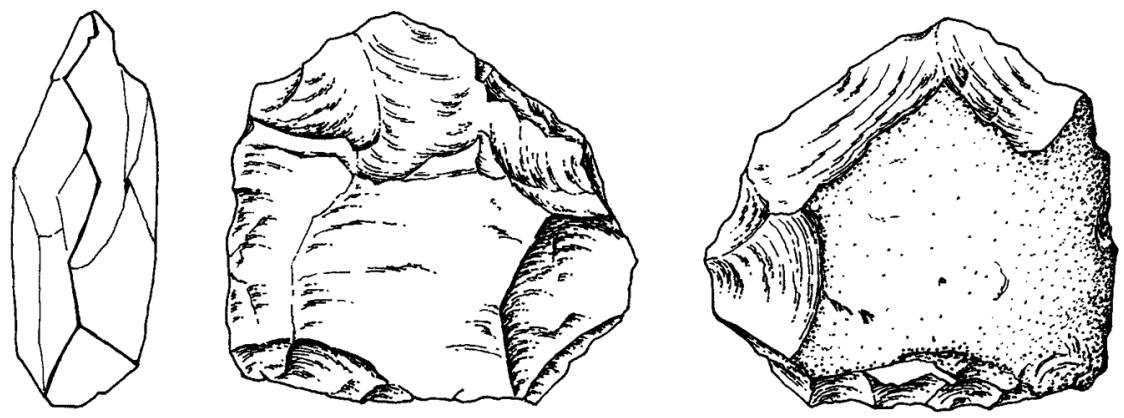

12

Fig. 4. Núcleo discoide (procedente de la prospección).
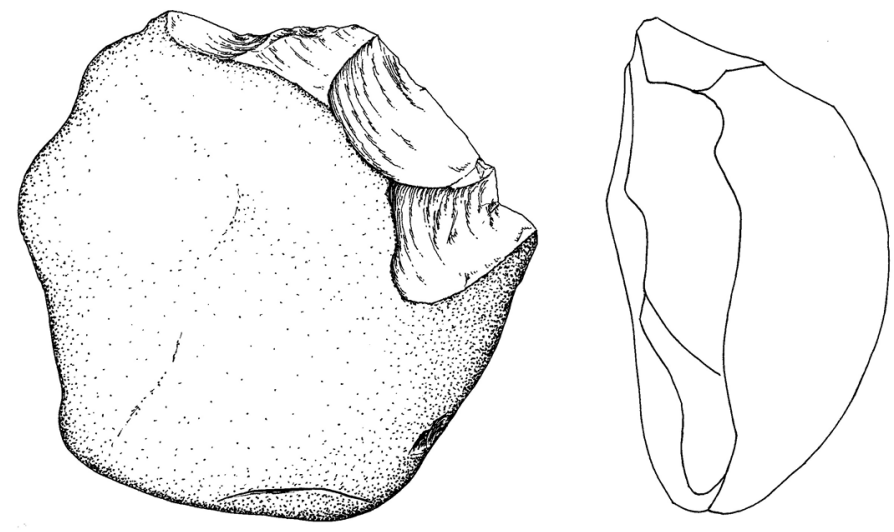

6

Fig. 5. Canto trabajado unifacial (procedente de la prospección).
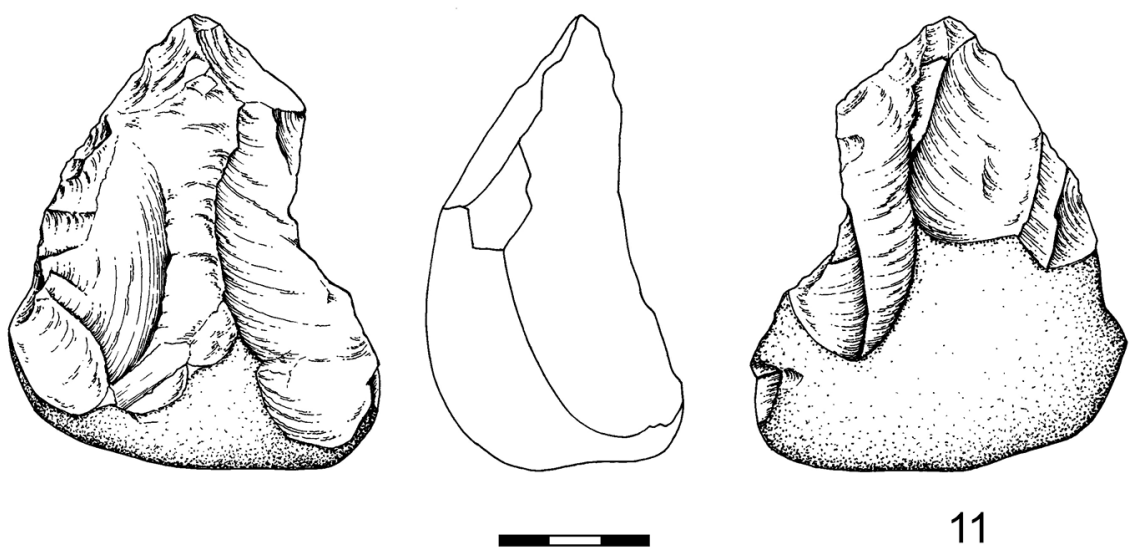

Fig. 6. Bifaz subtriangular (procedente de la prospección). 

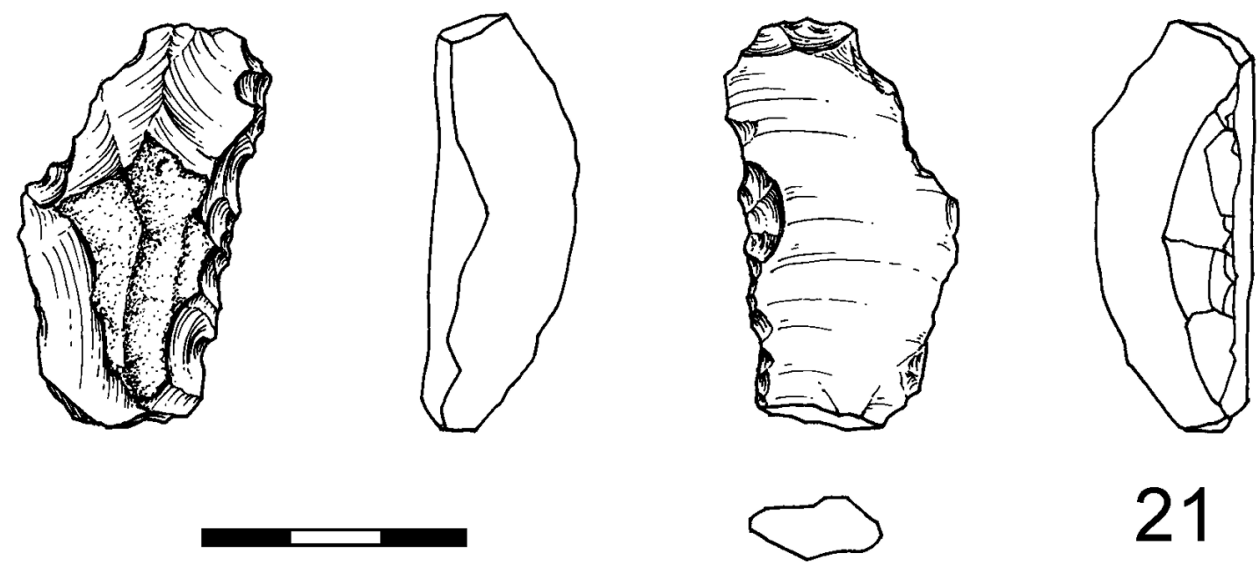

Fig. 7. Raedera simple recta (procedente de la prospección).
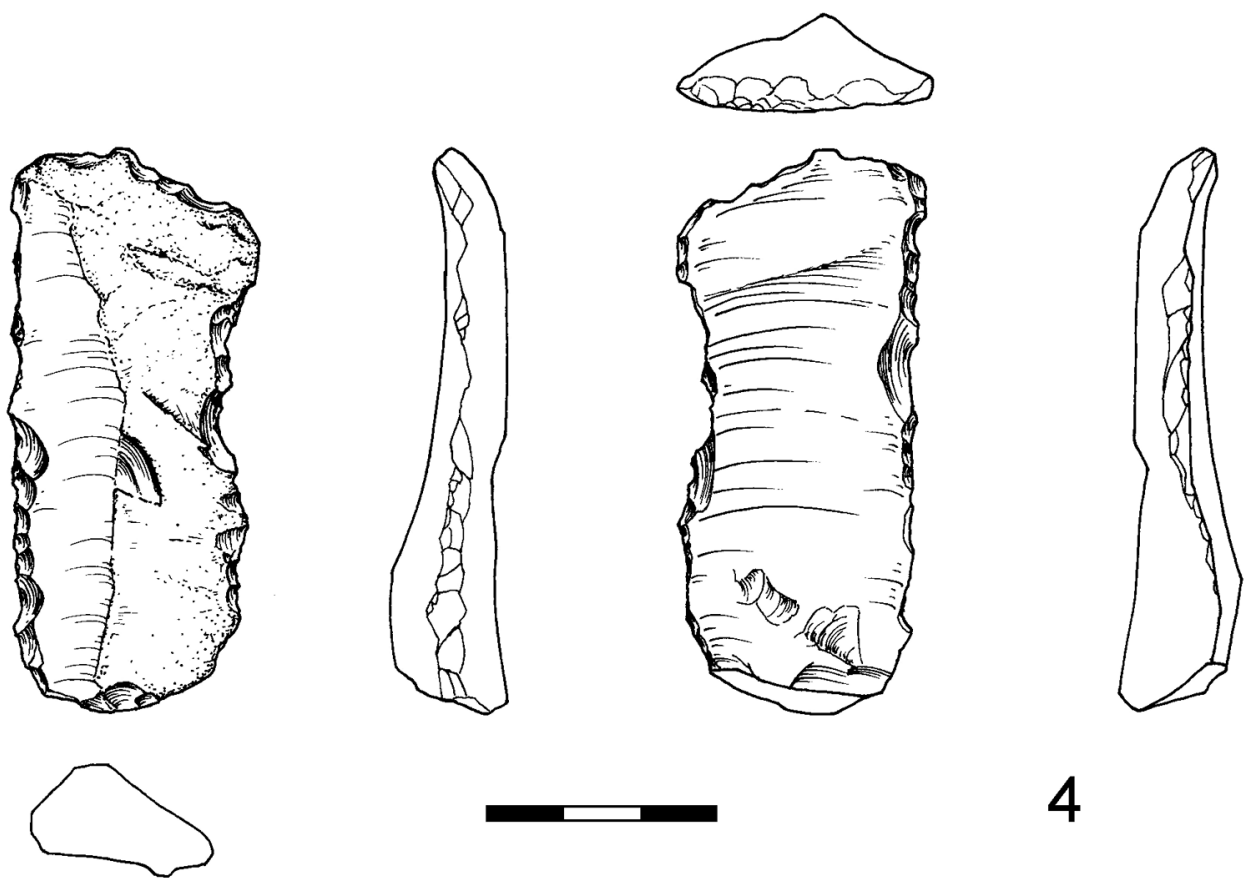

Fig. 8. Raspador (procedente de la prospección). 


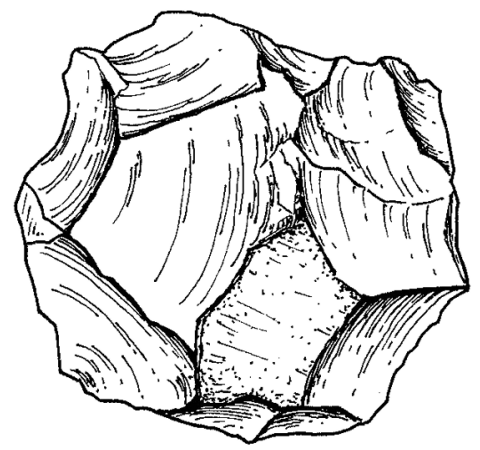

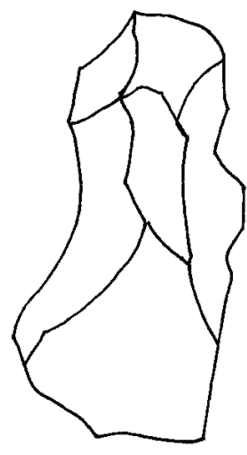

$3 \mathrm{~cm}$

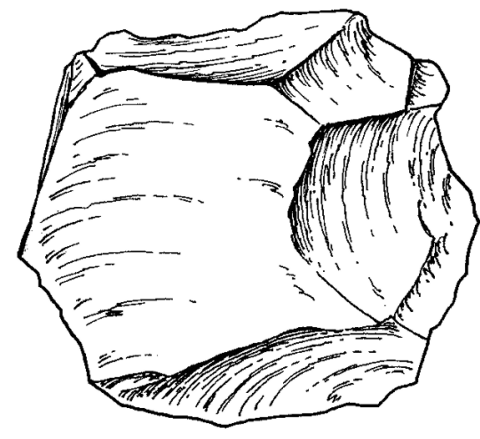

5

Fig. 9. Núcleo discoide (procedente de la excavación).
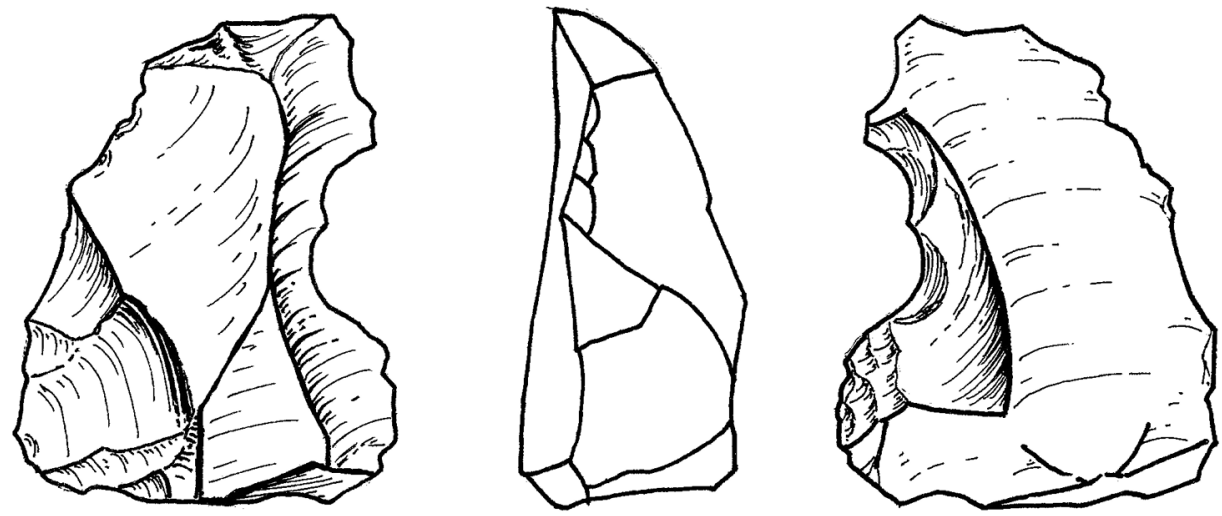

$3 \mathrm{~cm}$

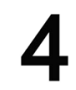

Fig. 10. Muesca con retoque denticulado (procedente de la excavación).

\section{BIBLIOGRAFIA}

Alberd, M. T. (Coordinadora) (1985): Geología y Paleontología del Terciario continental de la provincia de Madrid. Servicio de Publicaciones CSIC.

Antona del VaL, V. (1993): «Inventario y protección del Patrimonio Arqueológico en la Comunidad de Madrid». En Jimeno, A., Val, J. M. del y Fernández, J. J. (eds.): Inventarios y Cartas Arqueológicas. Homenaje a Blas Taracena. Junta de Castilla y León, Valladolid, pp. 239-245.

Baena, J., Conde, C., Gamazo, M., Sesé, C., y Soto, E. (2002): «Repertorio de yacimientos paleolíticos en el Manzanares y Jarama». En Bifaces y Elefantes. La Investigación del Paleolítico Inferior en Madrid. Zona Arqueológica 1, pp. 461-491. 
Bordes, F. (1988): Typologie du Paleolithique ancien et moyen. Presses du CNRS, París.

CABALleRo ZoredA, L. (Director) (1984): Inventario de los yacimientos de valor arqueológico y delimitación cartográfica de sus áreas de protección. Comunidad de Madrid. ECA-84, Comunidad de Madrid.

Calvo, J. P., Alonso Zarza, A. M. y García del Cura, M. A. (1989). «Sedimentología de los complejos lacustres miocenos de la Cuenca de Madrid». Acta Geológica Hispánica 24, pp. 281-298.

Fuster, J. M., Calvo, J. P. y Pérez-González, A. (1998): La geología de la región de Madrid. En Durán, J. J. (ed.) S. G. E. Madrid.

Junco, F. y CALvo, J. P. (1983): Geología de España. Tomo II, IGME, pp. 534-543.

MerinO, J. M. ${ }^{a}$ (1994): Tipología lítica. Munibe (Antropologia - Arkeologia), Suplemento n. ${ }^{\circ}$, Sociedad de Ciencias Aranzadi, San Sebastián.

Pérez-González, A. (1994): «La depresión del Tajo». En Gutiérrez Elorza, M. (ed.): Geomorfología de España, pp. 389-434. Editorial Rueda. Madrid.

Pérez-González, A. y Uribelarrea del Val, D. (2002): “Geología del Cuaternario de los valles fluviales del Jarama y Manzanares en las proximidades de Madrid». En Bifaces y Elefantes. La Investigación del Paleolítico Inferior en Madrid. Zona Arqueológica 1, pp. 302-317.

Rubio, S., Panera, J., Martos, J. A., Santonja, M. y Pérez-González, A. (2002): «Revisión crítica y síntesis del Paleolítico de los valles del Manzanares y Jarama». En Bifaces y Elefantes. La Investigación del Paleolítico Inferior en Madrid. Zona Arqueológica 1:, pp. 338-355.

Rubio, S., PANeRA, J. y MARTOS, J. A. (1999): «Autopistas, Ferrocarriles y Bifaces: ¿nuevas perspectivas para la investigación del Paleolítico en los ríos Manzanares y Jarama?». Espacio, Tiempo y Forma, Serie I, Prehistoria y Arqueología 12, pp. 67-79.

SANTONJA, M. y QUeRol, M. ${ }^{a}$ A. (1977): «Yacimientos Paleolíticos del Valle del Jarama». Boletín de la Asociación de Amigos de la Arqueología 8, pp. 4-9

- (1979): «El Achelense en las terrazas del Manzanares y Jarama. Bases para una interpretación» Actas del XV Congreso Nacional de Arqueología (Lugo 1977), pp. 57-68. Zaragoza.

- (1991): «El sitio de ocupación achelense de Áridos 2. Descripción general y estudio de la industria lítica». En VV.AA. Al encuentro de Arganda, Delegación de Cultura y Educación, Ayuntamiento de Arganda del Rey, pp. 25-35.

- (1991): «Yacimientos de la terraza de Aridos: proceso de excavación». En VV.AA. Al encuentro de Arganda, Delegación de Cultura y Educación, Ayuntamiento de Arganda del Rey, pp. 13-24.

Santonja, M., López Martínez, N. y Pérez-González, A. (1980): Ocupaciones Achelenses en el Valle del Jarama (Arganda, Madrid). Arqueología y Paleoecología, I. Diputación Provincial de Madrid.

Silva, P. G., Palomares, M., Rubio, F.; Goy, J. L., Hoyos, M., Martín Serrano, A., Zazo, C. y Alberdi, M. T. (1999): «Geomorfología, estratigrafía, paleontología y procedencia de los depósitos arcósicos cuaternarios de la depresión Prados-Guaten (SW Madrid)». Cuaternario y Geomorfología 13, n. 1-2, pp. 79-94. 